\title{
Mulheres nos especiais Bah!: Identidade gaúcha e representação feminina
}

\section{Mariana Nogueira Henriques}

Mestre; Universidade Federal de Santa Maria, Santa Maria, RS, Brasil

mariananhsm@yahoo.com.br

\section{Flavi Ferreira Ferreira Lisbôa Filho}

Doutor; Universidade Federal de Santa Maria, Santa Maria, RS, Brasil

flavilisboa@gmail.com

\begin{abstract}
Resumo
O trabalho busca analisar de que forma a identidade feminina é representada na RBS TV, com base no discurso enunciado pelos programas televisivos Bah! Um programa muito gaúcho e Bah! Eu sou do Sul. A partir de uma análise cultural, tendo como operador analítico o circuito da cultura de Johnson, busca-se relacionar como se dá a presença e a representação das mulheres em um contexto tradicionalista. Observa-se que o programa, ao mesmo tempo em que rompe com a premissa da subordinação feminina, evidencia o estereótipo mais difundido do gaúcho.
\end{abstract}

\section{Palavras-chave}

Estudos culturais. Gênero. Representação.

\section{Introdução}

A televisão, entre as mídias atuais, é a mais popular e a principal forma de obtenção de informações e entretenimento por parte da população. No Brasil, de acordo com dados veiculados no site do Instituto Brasileiro de Geografia e Estatística (2010), no total das moradias do país, 95,1\% dos domicílios têm televisão, ou seja, em nove de cada dez lares, o aparelho está presente. A partir daí, entende-se que a TV torna-se uma porta-voz da cultura, local onde ela se expressa, se reconhece, se configura e se reconfigura permanentemente. Desse modo, ao longo das últimas décadas, a TV modificou hábitos, costumes, valores e 
comportamentos da sociedade, tornando-se uma das grandes responsáveis por construir imaginários sociais e identidades culturais.

Devido sua ampla abrangência, transita em uma escala que vai do global às pequenas comunidades, e é nessas últimas, principalmente, que a televisão pode tornar-se porta-voz e espaço de reconhecimento, o que garante o êxito das televisões regionais. Em um estado como o Rio Grande do Sul, em que as questões culturais e identitárias são fortemente valorizadas, as televisões regionais auxiliam na representação e na afirmação da identidade hegemônica gaúcha. A partir dessa perspectiva, os programas Bah! Um programa muito gaúcho e Bah! Eu sou do Sul, apresentados no dia 20 de setembro ${ }^{1}$ de 2013 e 2014, respectivamente, ricos em elementos simbólicos e especificidades da cultura gaúcha, podem revelar intencionalidades políticas, culturais e econômicas, características da mídia televisiva.

Neste contexto, destaca-se a apresentação feminina dos programas que são transmitidos de dois locais comumente associados à figura masculina, do Centro de Tradições Gaúchas e do Acampamento Farroupilha. Na primeira edição, o especial foi apresentado por Carla Fachim e Shana Müller e, na segunda, por Cristina Ranzolin e Rodaika Dienstbach. As duas edições contaram com a presença de Neto Fagundes como um terceiro apresentador. Com base nisso, valorizando as relações entre comunicação e cultura, a pesquisa visa, por meio dos estudos culturais, aliado ao conceito de identidade e gênero, analisar de que forma a identidade feminina é representada na RBS TV, a partir do discurso enunciado pelos programas televisivos Bah!, em um contexto em que a identidade regional é fortemente marcada e masculina. Para tal, inicialmente, aborda-se a perspectiva dos estudos culturais aliada aos estudos de gênero. Posteriormente, compreende-se essa relação no contexto gaúcho. Utiliza-se, então, do protocolo metodológico de Johnson (2006) que relaciona, em um circuito, a produção, os textos, as leituras e as culturas vividas, possibilitando uma análise abrangente do produto audiovisual.

\section{Estudos Culturais e Estudos de Gênero}

Os estudos culturais têm início no final da década de 1950, com os trabalhos de Richard Hoggart, Raymond Williams e Edward Thompson. Esses primeiros estudiosos começaram a questionar o estabelecimento de hierarquias entre formas e práticas culturais, ordenadas a partir de oposições como cultura alta/baixa, superior/inferior, entre outras

\footnotetext{
${ }^{1}$ Data em que se celebra a Revolução Farroupilha no Rio Grande do Sul.
} 
binariedades (ESCOSTEGUY, 2001). Percebe-se, então, que entre os objetivos dos estudos culturais, está a ideia de revelar os discursos marginais, não oficiais, ou daqueles que propriamente não têm voz. Em 1969, se junta ao grupo Stuart Hall que incentivou o desenvolvimento de estudos etnográficos, dos meios de comunicação e das práticas de resistência das subculturas. Ao longo dos tempos, esse campo foi englobando autores, pensadores e temas diversos.

Nos anos 1970, incorporam-se às questões trabalhadas pelos estudos culturais e pelos estudos feministas, com questionamentos referentes à identidade e seu não determinismo apenas por questões culturais, mas também, de gênero. No entanto, a incorporação dessa temática, mesmo que apreciada por muitos pensadores, não se deu de forma fácil, já que, conforme explica Hall (2003), quando do início dos trabalhos feministas, percebeu-se que, mesmo dentro do próprio Centro, ainda era forte a presença de um poder patriarcal, que se sentiu afrontado com as novas perspectivas sociais. Ou seja, mesmo em um espaço em que se buscava valorizar culturas e enfrentamentos, os estudos feministas sofreram resistência e oposição, o que fez com que ganhassem visibilidade apenas no final da década de 1970.

Foi neste contexto de tensão e questionamentos que o termo feminismo surge com o objetivo de problematizar as diferenças sociais entre homens e mulheres e a desigualdade de gênero como uma construção social. Assim, nos anos 1970, o conceito de gênero começa a ser utilizado como uma forma de diferenciação entre o sexo como algo biológico e o gênero como resultado de construções sociais e culturais. Essa diferenciação era uma forma de enfrentar o determinismo biológico, segundo o qual as características consideradas femininas eram derivadas naturalmente do seu sexo.

Paralelamente aos estudos culturais de gênero britânicos, outros autores e pesquisadores também se dedicam a estudar a temática. Simone de Beauvoir (1970), nesse sentido, afirma que a mulher sempre foi considerada "o outro", sendo, então, inferior ao homem, por ser o seu oposto, isto é, o sexo frágil. Em contraposição a essa ideia, o conceito de gênero surge como sendo um sistema social, cultural, psicológico e literário constituído a partir de ideias, comportamentos, valores e atitudes associadas ao masculino e ao feminino (SCHMIDT, 1994). Dessa forma, busca-se complexificar o debate sobre as diferenças entre homens e mulheres, englobando contextos e definições para além, dando suporte a diversos tipos de gênero que podem existir individualmente. Nesse viés, contemporaneamente, Butler (2015) afirma que ser mulher ou homem não significa que isso seja tudo que essa 
pessoa possa ser, já que em um único ser coexistem elementos de diferentes contextos em que ele se insere: históricos, de classe, de raça, étnico, regionais e identitários. Isso impossibilita com que tomemos a identidade de uma mulher como representativa de todas as mulheres. Ou seja, "[...] resulta que se tornou impossível separar a noção de gênero das interseções políticas e culturais em que invariavelmente ela é produzida e mantida." (BUTLER, 2015, p. 21). Contudo, ocorre que, desde pequenos, as pessoas são "acostumadas" a fazer distinções apenas entre o feminino e o masculino, "meninas gostam de rosa e brincam de boneca; meninos gostam de azul e brincam de carrinho". Essas distinções, ao longo do tempo, vão definir o "feminino" como inferior ao "masculino" e, a partir disso, são transformadas em desigualdades hierárquicas por meio de discursos masculinos sobre a mulher.

Pensar o gênero através das relações sociais, baseado nas diferenças entre feminino e masculino, envolve também problematizar símbolos e conceitos culturalmente disponíveis em nossa sociedade. "Esses conceitos são expressos nas doutrinas religiosas, educativas, científicas, políticas ou jurídicas e tipicamente tomam a forma de uma oposição binária que afirma de forma categórica e sem equívoco o sentido do masculino e do feminino." (SCOTT, 1995, p. 86). O problema deste binarismo reside na exclusão de outras possibilidades de interpretação e na escolha de uma posição dominante para ser a representante da figura da mulher, como se essa fosse um consenso social. Dessa forma, é necessário buscar por um arranjo político e institucional que desconstrua essas oposições binárias que definem o que é ser homem ou mulher de modo antagônico, atribuindo valores a cada um. É preciso, então, considerar a formação de identidades de gênero que se organizem através de representações sociais e culturais.

Nesse sentido, Farah (2004) chama atenção para o caráter histórico das diferenças entre gênero e construção social das percepções sexuais, destacando a necessidade de romper com a homogeneização desses campos - o masculino e o feminino - e reconhecer a diversidade existente no interior de cada um deles. Sem isso, as atuais relações de gênero fazem com que as desigualdades entre homens e mulheres tornem-se desigualdades de poder. "O padrão dominante nas identidades de gênero de adultos envolve uma situação de subordinação e de dominação das mulheres, tanto na esfera pública como na privada." (FARAH, 2004, p. 48). Desde a infância, as pessoas são expostas a diversas situações que naturalizam as questões de gênero, na própria família, na escola e até na mídia. Essas situações, muitas vezes, incentivam e reforçam papéis específicos dos gêneros. 


\section{Identidade e gênero no Rio Grande do Sul}

0 termo identidade, bem como seu conceito, é utilizado e interpretado a partir dos mais variados campos do saber. Ele pode ser entendido a partir de nossa essência genética, o que nos individualiza e nos faz ser únicos e, ao mesmo tempo, no campo social e antropológico, o que nos une e nos assemelha aos demais. Neste sentido, compreende-se identidade como um conjunto de características que identificam e servem como forma de reconhecimento de um grupo social. Castells (1999, p. 23) explica as identidades como frutos de significados e trocas de experiências de um povo, e sua construção " [...] vale-se da matéria-prima fornecida pela história, geografia, biologia, instituições produtivas e reprodutivas, pela memória coletiva e por fantasias pessoais, pelos aparatos de poder e revelações de cunho religioso.". Como as matérias primas, descritas por esse autor, são mutáveis, isso nos leva a compreender que as identidades também não são fixas e estanques.

Por outro lado, cabe destacar que as identidades, apesar de seu caráter efêmero, não raras vezes, são relativamente estáveis (CUCHE, 2002). Dizemos, então, que a identidade de um indivíduo caracteriza-se de acordo com suas vinculações sociais, permitindo com que se localize e seja localizado socialmente. Dessa forma, o conjunto de características semelhantes que unem um determinado grupo de pessoas é o que o diferencia de outros grupos. É possível afirmar, então, que as identidades são marcadas pela diferença (WOODWARD, 2000), ou seja, diferenciamo-nos de outros povos e de outras culturas pelas nossas semelhanças, no modo de pensar, agir, falar, etc., nas nossas representações simbólicas. Mostramo-nos individual ou coletivamente, através de signos, símbolos e linguagens, que nada mais são do que a representação da nossa identidade.

Aferimos, assim, que a identidade, bem como a representação, buscam gerar um sentimento de pertença a um determinado grupo. Nesse sentido, a mídia, a partir de seus modos de produção, tenta criar imagens e representações que gerem identificação com seus telespectadores. No entanto, muitas vezes, essa representação não dá conta da pluralidade identitária de seu público.

Insere-se, aqui, o conceito de representação que, segundo Hall (1997), é usar a linguagem para apresentar o mundo de uma maneira significativa para o outro. Tais significados estão permeados por ideologias e pensamentos partilhados entre quem apresenta e quem consome o produto cultural. Dessa forma, os discursos e os sistemas de 
representação constroem os lugares a partir dos quais os indivíduos podem falar e se posicionar.

Assim, muitos programas televisivos que têm seu viés voltado para a cultura gaúcha apelam para representações hegemônicas do povo do estado, sendo hegemonia aqui entendida, a partir de Antonio Gramsci (2002), como uma complexa relação de forças políticas, sociais e culturais, sendo um tipo particular de dominação em que uma classe a detém mediante a produção de uma ideologia que organiza a ordem social vigente. Quanto mais difundida a ideologia, mais sólida será a hegemonia. Já Williams (1979, p. 113), a compreende como um sistema de significados e valores: "A hegemonia [...] é todo um conjunto de práticas e expectativas sobre a totalidade da vida: nossos sentidos e distribuição de energia, nossa percepção de nós mesmos e nosso mundo. É um sistema de significado e valores - constitutivo e constituidor.". Ou seja, estabelece um senso de realidade para determinada sociedade, funciona, conforme exposto pelo autor, como uma espécie de "cultura", mas uma cultura que determina domínios e subordinações. Dessa forma, ao destacar características principais do gaúcho, modos de vida e pensamento, cria-se uma representação dessa figura que, ao longo do tempo, tornou-se hegemônica, ditando formas de ser e modos de agir "do gaúcho", ocultando e subordinando uma grande variedade cultural e identitária existente no estado.

A identidade hegemônica que temos hoje no Rio Grande do Sul vem se forjando desde a segunda metade do século XIX e, desde então, estudiosos e historiadores têm se ocupado a pesquisar questões relativas a ela. Contribuíram com isto, além da tradição oral, a literatura, a imprensa, a música, o Movimento Tradicionalista Gaúcho (MTG) e, recentemente, os diversos suportes midiáticos, com destaque para as televisões locais, que auxiliaram para sua disseminação de uma forma mais abrangente.

A despeito de uma diversidade cultural no estado, engendrou-se uma figura única do gaúcho que é, constantemente, evocada para definir o povo do Rio Grande do Sul. Figura esta, predominantemente masculina, remete ao homem rural, das lidas campeiras, trajado com bota e bombacha e com seu inseparável companheiro, o cavalo. Traz, ainda, a virilidade, a valentia, e o orgulho de seus feitos e realizações dos tempos das guerras e revoluções. As mulheres, nessa representação, ficam em segundo plano e, mesmo em situações em que é exaltada como heroína, ela apresenta atributos próprios da figura masculina. Ou seja, no Rio Grande do Sul, os valores, as representações e os significados construídos em torno da cultura regional tomam o masculino como referência. 
A imagem do gaúcho contemporâneo está intimamente relacionada à figura difundida pelo MTG, a partir dos anos 1940. Essa figura incorporou-se ao imaginário social, carregando, ao longo das décadas, diversos estereótipos que formaram um sujeito e que, por consequência, forjou uma representação dessa identidade, tornando-a hegemônica. Esta imagem relaciona-se a de um povo guerreiro, batalhador, orgulhoso, viril, com princípios, ética, moral e força. Legado esse que recebeu devido a seu histórico de lutas e enfrentamentos, como na Revolução Farroupilha (de 1835-45), Guerra do Paraguai (de 1864), Revolução Federalista (de 1893-95), Coluna Prestes (de 1925), Revolução de 30, "Legalidade" em 1961. Todo esse cenário serviu de base para a instauração de uma sociedade patriarcal, militarizada e pecuarista no estado, em que, de acordo com Pesavento (1991), as características mais valorizadas eram a força, a coragem e a destreza. Era preciso estar preparado para enfrentar o inimigo, para cuidar dos rebanhos de gado e para cavalgar longas distâncias.

Esse conjunto de elementos ajudaria a explicar esse caráter um tanto fogoso que já teria se incorporado ao inconsciente coletivo gaúcho. [...] As peculiaridades do Rio Grande do Sul contribuem para a construção de uma série de representações em torno dele que acabam adquirindo uma força quase mítica que as projeta até nossos dias e as fazem informar a ação e criar práticas no presente. (OLIVEN, 1992, p.47).

Segundo o referido autor, este tipo social "gaúcho" seria fruto do posicionamento geográfico do estado, que está em uma área limítrofe do Brasil, ao lado de países como Argentina e Uruguai. Ou seja, "O gaúcho é socialmente um produto do pampa, como politicamente é um produto da guerra." (OLIVEN, 1992, p. 51). Neste sentido, de acordo com Woodward (2000, p. 27), a afirmação das identidades é historicamente específica, ou seja, uma das formas pelas quais as identidades estabelecem-se é por meio do apelo a antecedentes históricos. "Ao afirmar uma determinada identidade, podemos buscar legitimá-la por referência a um suposto [...] passado glorioso, [...] que poderia validar a identidade que reivindicamos.". No caso da identidade gaúcha, essa construção está fortemente relacionada à Revolução Farroupilha que, em seus dez anos de duração (18351845), forneceu vasto material para que fosse moldada a identidade do povo sul-riograndense. Ocorre, porém, que nesta referida representação, a mulher foi excluída da história, perdeu a voz e a ação. Pesavento (1991, p. 59) afirma que “[...] a historiografia oficial gaúcha compunha a imagem de um passado essencialmente masculino, linear e heroico, adequado a uma sociedade onde os homens ditavam as leis e ocupavam os cargos de mando.". 
Essa figura pode ser visualizada, por exemplo, em uma imagem que é tida como a "representação do povo do gaúcho" - a estátua do Laçador ${ }^{2}$ - que busca reproduzir o "autêntico" gaúcho, inspirada em Paixão Côrtes (Figura 1). Esse fato corrobora com o pensamento de Jacobina e Kühner (1998) que afirmam que, desde as primeiras civilizações, a história da humanidade é marcada pelos personagens masculinos, que eram guerreiros, heróis e artistas.

Figura 1- Estátua do Laçador

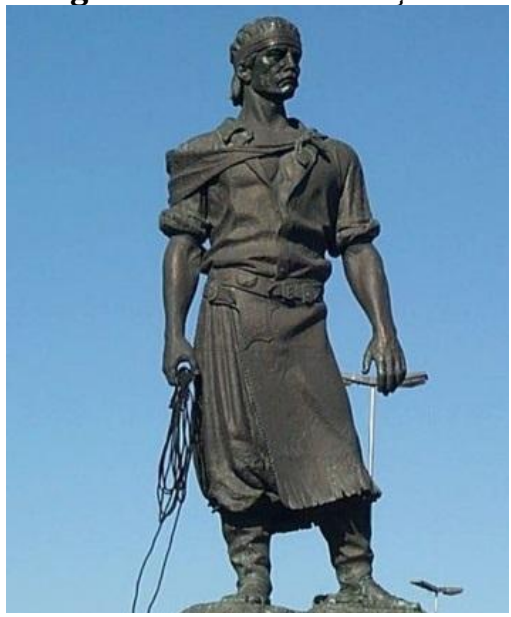

Fonte: Côrtes (2011)

Nos anos 1940, quando o país vivia um intenso processo de desenvolvimento, progresso econômico e internacionalização, Paixão Cortes ${ }^{3}$ reúne o Grupo dos Oito ${ }^{4}$, em uma tentativa de reacender as características ditas gaúchas 5 . Antônio Siqueira, um de seus integrantes, em entrevista para a primeira edição de Bah!(2013), sobre a criação do tradicionalismo, diz que "A gente já (sic) tava cheio desses programas de influência de Cowboy, então nós resolvemos terminar com isso.". Assim, no ano de 1948, foi criado o primeiro Centro de Tradições Gaúchas (CTG), o 35, em Porto Alegre6 , como um local

${ }^{2}$ A estátua foi criada em 1954, para a exposição do IV Centenário de fundação da cidade de São Paulo, em que foi realizado um concurso público para a execução de uma escultura que servisse como símbolo de cada Estado. Representando o Rio Grande do Sul, foi criada a estátua do Laçador, inspirada em Paixão Côrtes. A estátua foi definida como Símbolo Oficial de Porto Alegre, em 1992. Atualmente, localiza-se no Sítio do Laçador, na Avenida dos Estados no bairro São José, na zona norte da cidade, próxima ao Aeroporto Salgado Filho. Criada pelo escultor pelotense Antônio Caringi, ela representa o gaúcho tradicionalmente pilchado.

${ }^{3}$ Folclorista, escritor, compositor e pesquisador gaúcho. Serviu de inspiração para a criação da estatura do Laçador, definido como Símbolo Oficial de Porto Alegre, em 1992.

${ }^{4}$ Integravam o Grupo dos Oito: Antonio João de Sá Siqueira, Fernando Machado Vieira, João Machado Vieira, Cilço Campos, Ciro Dias da Costa, Orlando Jorge Degrazzia, Cyro Dutra Ferreira e João Carlos Paixão Côrtes.

${ }^{5}$ Antes disso, João Cezimbra Jacques, historiador, já havia publicado um livro sobre costumes do Rio Grande do Sul e, em 1898, fundou o Grêmio Gaúcho, uma espécie de projeto de CTG. A proposta é retomada com mais força no ano de 1947, através do Grupo dos Oito.

${ }^{6}$ O primeiro Centro de Tradições Gaúchas foi o 35 CTG fundado em 24 de abril de 1948, por Paixão Côrtes e o "Grupo dos Oito", a partir da criação do Departamento de Tradições Gaúchas do Colégio Júlio de Castilhos, em Porto Alegre, no ano anterior. 
exclusivo de homens e com o objetivo de perpetuar costumes e tradições gaúchas. Esta figura masculina, dentro do CTG é caracterizada pelo peão e pelo patrão, que se coloca como protagonista do movimento. Cabe destacar, ainda, que na criação dos primeiros CTGs, as mulheres não foram aceitas nos encontros. Somente após dois anos de existência dos Centros é que algumas foram convidadas a participar das reuniões tradicionalistas, porém, com funções estipuladas e apropriadas às suas "características femininas".

Tornou-se necessário, desta forma, construir, também, uma figura feminina que representasse o tradicionalismo, dando origem à prenda. Essa imagem, de acordo com Dutra (2002), foi criada a partir de discursos recorrentes sobre a mulher no estado, baseado em uma doutrina católica e concepções positivistas, reafirmando uma moral conservadora do movimento. Esta mulher concebida deveria ser pura, ingênua e graciosa. Ou seja, na idealização da prenda, criaram-se um conjunto de valores que deveriam fazer parte da "essência feminina", como a delicadeza, a beleza, a simpatia e o recato.

Essa construção, por parte do Movimento Tradicionalista Gaúcho (MTG), retoma a ideia apresentada por Pesavento (1991) de que as mulheres, na historiografia, eram sempre deixadas em segundo plano, quando não ocultadas. Eram consideradas frágeis e submissas. Contudo, para além de uma identidade hegemônica e de registros masculinizados, surge outra figura da mulher, diferente da difundida. São diversos os registros encontrados em cartas que relevam que muitas mulheres eram participantes ativas, não só na direção das estâncias, mas também conhecedoras de políticas e táticas de guerra, auxiliando muitos homens em suas estratégias de batalha (PESAVENTO, 1991). E tal situação não era incomum. Com tantos conflitos, os homens ausentavam-se se suas casas por longos períodos de tempo, e quem assumia o controle das atividades econômicas e financeiras eram as mulheres, as estancieiras. Além disso, não raras vezes, participavam de forma mais ativa nos conflitos, quando cediam suas casas para abrigos de soldados, depósito de armamentos ou como postos de correio, ainda doavam bens e dinheiros para a causa - imagem oposta aquele estereótipo feminino idealizado.

\section{As mulheres em Bah!}

Os estudos culturais compreendem que os meios de comunicação de massa agem de forma dinâmica e ativa na construção e consolidação de identidades e estabilidade social. Neste sentido, Hall (2003) afirma que, quando as práticas de significação começam a ser investigadas, ocorre uma mudança nas análises dos media, ou seja, compreende-se que o 
discurso televisivo não é neutro e está, intimamente, relacionado às estruturas de produção de sentido.

A mídia televisiva, para os estudos culturais, corresponde a um dos principais locais através dos quais a cultura circula e é produzida. Com base nisso, Rocha (2011, p.10) afirma que "[...] estudar a TV não significa simplesmente dedicar-se àquilo que ela transmite, mas, de forma específica, significa atentar-se para o próprio processo pelo qual os conteúdos se realizam no fluxo televisivo.". Ou seja, observar o fluxo televisivo desde a produção dos textos até a recepção, no momento e no contexto em que acontecem. Analisar televisão, a partir dos estudos culturais, é compreender que a produção, a circulação e o consumo dos produtos culturais podem ser pensados por meio de um circuito em que cada um dos momentos depende dos outros e, ao mesmo tempo, é indispensável para o todo. Tem-se que considerar as práticas interpretativas da audiência e pensar em uma relação de influência direta da produção/textos na recepção. Desse modo, apresenta-se o circuito da cultura de Johnson (2006) (Figura 1), que será abordada enquanto protocolo metodológico para analisar os programas Bah!.

Figura 2 - Circuito da Cultura de Johnson

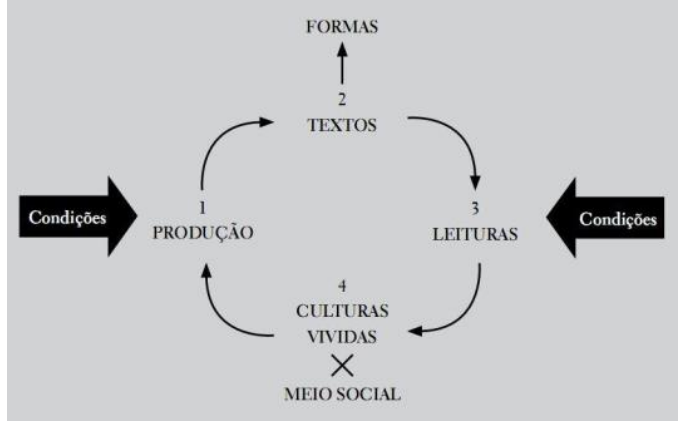

Fonte: Escosteguy (2007)

No circuito, em produção estão centradas as preocupações com a organização das formas culturais, ou seja, aquilo que reflete diretamente no produto midiático. Aqui, devemse incluir também aspectos subjetivos, isto é, pensar na produção relacionada às culturas vividas e suas influências. Sendo assim, deve-se considerar o contexto em que se insere, já que, "[...] as condições de produção incluem não apenas os meios materiais [...], mas um estoque de elementos culturais já existentes, extraídos do reservatório da cultura vivida ou dos campos já públicos de discurso." (JOHNSON, 2006, p. 56). Realizou-se então, uma pesquisa exploratória, a fim de buscar uma aproximação com alguns aspectos relativos à produção. Aqui, consideraram-se as normas institucionais da RBS TV e o seu modus operandi. Além disso, a emissora já é conhecida por fortalecer a regionalização com diversos 
programas que apresentam elementos culturais de fácil reconhecimento e identificação, já que, desde a década de 1970, atua produzindo atrações com referências a uma identidade gaúcha. Os programas Bah! inserem-se nessa lógica já existente, por isso, seria um equívoco analisá-los isoladamente, sem considerar os diversos fatores que estão envolvidos em sua produção.

Em texto, está o modo como as formas simbólicas são tratadas para produzir significado. Centram-se aqui as análises textuais, discursivas e outras relacionadas ao produto midiático em si. Estudar o texto, de acordo com Johnson (2006, p. 75), permite identificar os repertórios narrativos básicos que organizam a sociedade, sendo ele "[...] apenas um meio [...], um material bruto a partir do qual certas formas (por exemplo, da narrativa, da problemática ideológica, do modo de endereçamento, da posição de sujeito, etc.) podem ser abstraídas.”. Assim, o texto passa a ser estudado não por ele próprio, mas pelas formas subjetivas que ele torna disponíveis. Aqui, como método, recorre-se à análise textual proposta por Casetti e Chio (1999), já que valoriza o material simbólico (signos, símbolos e figuras) dos programas, sem deixar de considerar os elementos estruturais. Os textos são compreendidos como elementos complexos, em que são reconhecidas as realizações linguísticas e comunicativas. Dessa forma, a análise textual não busca por unidades isoladas, mas pretende compreender as relações entre essas unidades e os seus significados. Ainda, a partir dela, é possível ir além do próprio texto, problematizando atitudes e valores de quem os cria, revelando o modo como algo é proposto e apresentado a uma audiência.

Com base nisso, pretende-se analisar o programa a partir de alguns aspectos principais, que dizem respeito a sua organização, como as diferenças entre as edições, o fio condutor das narrativas, as transformações entre elas, as especificidades, o figurino, a gestualidade e as falas. Sendo assim, o esquema proposto para este trabalho é dividido em três grandes categorias: cenas, sujeitos e texto.

Por culturas vividas, entende-se o meio social em que se pautam a produção e as leituras (ESCOSTEGUY, 2007, p. 120-121), é o contexto em que os programas inserem-se, abordado na seção anterior "Identidade e gênero no Rio Grande do Sul", na qual enfocamos aspectos sociais, históricos, culturais e identitários do estado. É a partir daqui que se criam as condições para o fazer televiso, que busca referências para suas produções e discursos. Este ponto torna-se particularmente importante, devido à escolha do objeto empírico de estudo, que tem forte ligação com o contexto histórico do Rio Grande do Sul, já que é um 
programa televisivo em comemoração à data de 20 de setembro, alusiva à Revolução Farroupilha, conflito esse, intimamente relacionado à formação de uma identidade cultural hegemônica gaúcha.

Nas leituras, estão relacionadas as práticas de recepção; é o espaço de produção de sentido. Deve ficar claro nosso posicionamento em relação à importância de se considerar as práticas da audiência ao se analisar produtos culturais televisivos. Entretanto, destaca-se que a temática principal dessa pesquisa centra-se nas representações identitárias femininas, com foco na produção.

A escolha específica desse programa, em suas duas edições, deu-se devido a sua riqueza em elementos simbólicos e especificidades da cultura gaúcha, que podem revelar intencionalidades políticas, culturais e econômicas, características intrínsecas da mídia televisiva. Além disso, buscam evocar sentimentos de orgulho e pertencimento a um grupo ou a uma comunidade. Produzidos pelo canal de televisão aberta para as comemorações da Revolução Farroupilha, a RBS TV buscou representar o gaúcho por meio de suas características culturais hegemônicas: a dança, a música, a culinária, as vestimentas e as linguagens e, além disso, trouxe consigo a forte presença feminina em um contexto identitário masculino.

Assim, para dar conta da produção, vale-se da pesquisa realizada sobre a emissora e sobre a própria produção do programa. Considerando que a RBS TV foi a primeira e, hoje, uma das principais emissoras regionais afiliadas da Rede Globo, ao longo do tempo, já consolidou uma linha de programação voltada para a cultura gaúcha. Neste cenário, as televisões regionais atuam como importante centro de afirmação e reforço das identidades locais. Para Hinerasky (2005), as emissoras regionais servem como um ambiente de reconhecimento e identificação para as populações das regiões em que operam, já que refletem e representam as imagens desses grupos. A RBS TV, nesse sentido, busca dar visibilidade às temáticas regionais, apresentando um gaúcho como representante dessa identidade do estado. Sendo assim, busca por meio de sua programação, anunciantes, imagens e linguagens, difundir uma identidade empresarial que a firme enquanto marca. Promove, então, a si própria e, neste processo, apresenta-se como a grande responsável por "mostrar o mundo dos gaúchos para os gaúchos", tornando-se a detentora da identidade gaúcha através de uma consolidada linha de programas com foco no regional. Dessa forma, os especiais utilizam-se de uma fórmula criada pela própria emissora. No Quadro 1, é possível visualizar de forma resumida algumas das características dos programas. 
Quadro 1 - Quadro resumo dos programas

\begin{tabular}{|c|c|c|}
\hline & $\begin{array}{c}\text { Bah! Um programa } \\
\text { Muito gaúcho }\end{array}$ & Bah! Eu sou do Sul \\
\hline Exibição & $20 / 09 / 2013$ & $20 / 09 / 2014$ \\
\hline Horário & $\begin{array}{c}\text { Sessão da Tarde - Globo } \\
\text { (sexta-feira) }\end{array}$ & $\begin{array}{c}\text { Programação local - RBS TV } \\
\text { (sábado) }\end{array}$ \\
\hline Duração do programa & 1h38min & 1h10min \\
\hline Apresentação & $\begin{array}{c}\text { Shana Müller } \\
\text { Carla Fachim } \\
\text { Neto Fagundes }\end{array}$ & $\begin{array}{c}\text { Cristina Ranzolin } \\
\text { Neto Fagundes }\end{array}$ \\
\hline Local de apresentação & $\begin{array}{c}\text { CTG Rancho da Saudade e } \\
\text { Acampamento } \\
\text { Farroupilha }\end{array}$ & \begin{tabular}{c} 
Acampamento Farroupilha \\
\hline
\end{tabular} \\
\hline
\end{tabular}

Fonte: Elaborado pela autora.

Inicialmente, é possível perceber que os programas especiais Bah! foram produzidos nos moldes do Galpão Crioulo, um dos programas mais tradicionais nesta linha, no ar desde 1982, na emissora. As semelhanças são observadas nos cenários, nos apresentadores e na direção, que inclui a diretora atual do Galpão Crioulo, Rosana Orlandi, e Silvio Barbizan, que também já dirigiu o programa.

Ainda, pode-se destacar que, estruturalmente, os dois programas Bah! assemelhamse, já que ambos apresentam um início com imagens referentes ao estado. A composição também se parece, visto que possuem duas apresentadoras acompanhadas por Neto Fagundes. Exibem reportagens e produções especiais variadas. Em relação ao conteúdo e ao fio condutor, eles apresentam diferentes elementos. 0 primeiro surge como algo novo. 0 seu roteiro não pode ser comparado a outros programas da emissora, não apresenta características factuais, mas sim, reportagens longas, com caráter explicativo e histórico. Já o segundo, exibido durante o horário de três outros programas tradicionais da grade da emissora, molda-se a esses formatos, adquirindo características de revista que, segundo Souza (2004), é uma espécie de programa que mescla diversos elementos, como reportagens, músicas, humor, esportes, interatividade e entradas ao vivo de repórteres. A participação de convidados na segunda edição também é mais restrita. Os dois programas assemelham-se ao evocar características ditas do gaúcho, mostrando sua coragem, valentia, 
honestidade, pioneirismo e orgulho por seus feitos e por viver no estado que, apesar de todos os problemas que enfrenta, ainda é visto como "o melhor lugar do mundo". Percebese, então, que a trama principal dos especiais desenvolve-se no sentido de evidenciar uma identidade, de gerar um sentimento de pertencimento ao Rio Grande do Sul. A mescla de elementos tradicionais e contemporâneos e de apresentadores atua na tentativa de atingir uma audiência ampla.

Esses elementos e o modo como já são conhecidamente organizados afetam diretamente os textos, que são observados a partir de três eixos principais, as cenas, os sujeitos e os textos verbais. Sendo assim, os programas Bah! também se assemelham ao Galpão Crioulo quando optam por cenários rústicos, que remetem aos galpões de estâncias, espaço importante onde a vida rural acontece e que podem ser observados tanto no CTG Rancho da Saudade, como no Acampamento Farroupilha, locais onde a presença feminina não era aceita ou onde as "mulheres de família" não deviam estar. Pode-se relacionar, então, a presença das apresentadoras nesse ambiente masculino com a crescente participação e aceitação das mulheres no mercado de trabalho, nos postos de comando, nos espaços públicos e na esfera política. Ainda, podemos comparar as atuações delas (apresentadoras) a patroas de um CTG, por estarem no comando das atrações. Esses locais que, anteriormente, eram associados ao homem, em que a presença feminina era desvalorizada e, por vezes, não aceita, passaram por grandes transformações - percebidas, também, no contexto cultural gaúcho. Tendo a mídia grande papel como meio de obter informações, atualizações, e como porta-voz de (alguns) discursos sociais, ao trazer quatro mulheres como apresentadoras dos programas tenta romper com uma hegemonia masculina7. Dando voz e visibilidade a elas, essa estratégia funciona como uma atualização das imagens associadas ao meio tradicionalista e dá força para que esses novos posicionamentos e a presença da mulher sejam melhores aceitos nesses meios.

Na composição desse cenário rústico, rodas de carretas, bancos baixos feitos de tocos de madeira, pelegos e lampiões misturam-se a muitos holofotes que se distribuem pelos espaços, além de grandes telões localizados ao fundo (Figuras 3 e 4).

Figura 3 - CTG Rancho da Saudade

\footnotetext{
7 Percebe-se essa tendência não apenas nos Bah!, mas em vários programas e emissoras distintas, em que os âncoras masculinos estão sendo substituídos por apresentadoras mulheres. Como é o caso do Jornal do Almoço e Globo Esporte, programas exibidos pela RBS TV.
} 


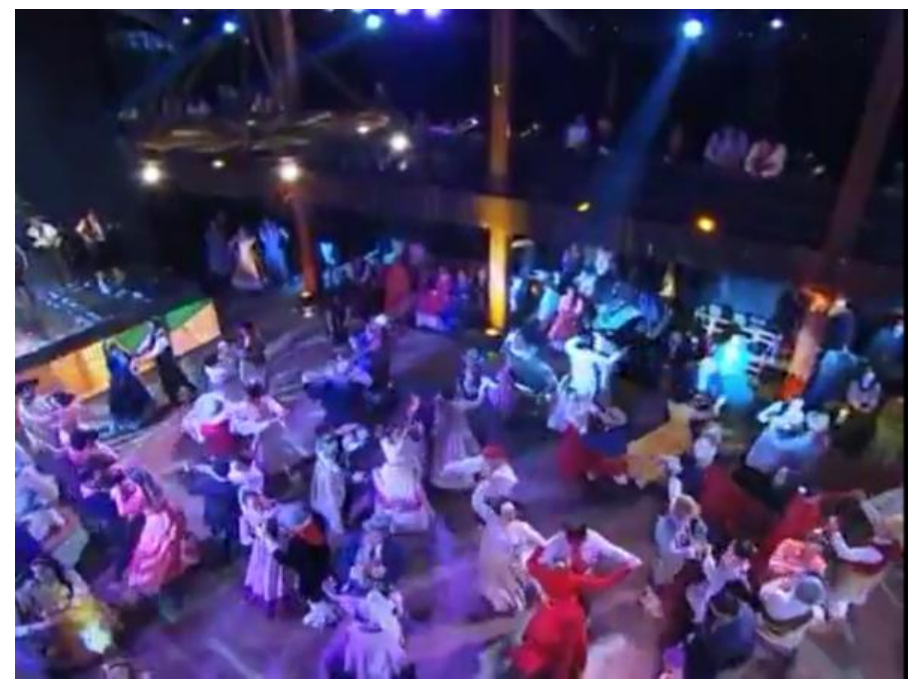

Fonte: Bah! Um programa muito gaúcho (2013).

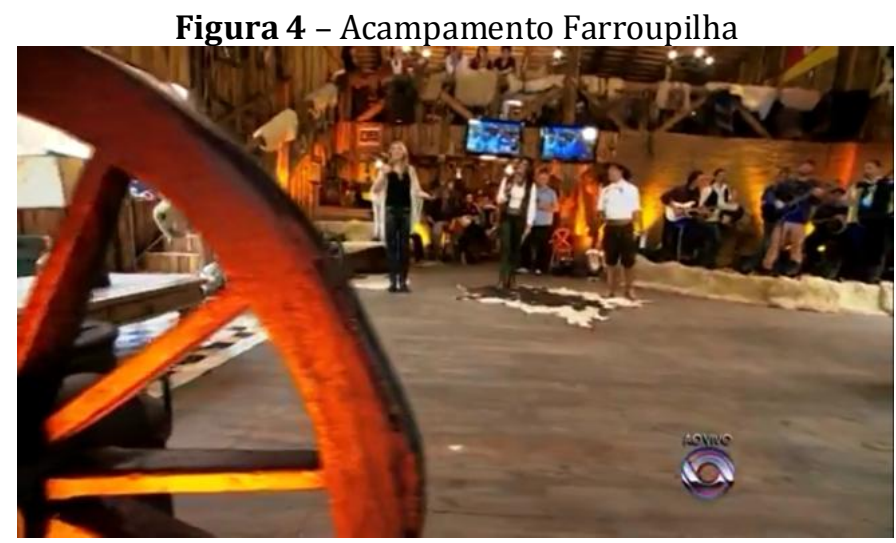

Fonte: Bah! Eu sou do Sul (2014).

Destaca-se, ainda, a escolha dos apresentadores dos especiais e a preponderância feminina. Neto Fagundes, nas duas edições, aparece como um terceiro apresentador, estando em segundo plano em relação à elas, que comandam a maior parte das atrações. Sua figura já dá sinais de certa abertura em relação aos costumes gaúchos mais tradicionais. Neto, de acordo com Lisboa Filho (2009), por meio de sua imagem dinâmica e jovial, seu tom de voz e sorriso sempre presente, dá mostras do que está sendo feito e construído em termos de (re)adequações da cultura gaúcha através de suas vestimentas, como o uso da bombacha castelhana, e readaptações de músicas gaúchas para outros ritmos.

Junto a Neto Fagundes, na primeira edição do programa Bah! (2013), está Shana Müller, cantora tradicionalista e também a primeira mulher a apresentar o Galpão Crioulo, a partir do ano de 2012. Essa participação, de acordo com Bortoluzzi et al. (2013, p. 7), “[...] representa a ação da atual mulher gaúcha, que busca autonomia enquanto sujeito social.". 
Carla Fachim, por sua vez, destoa dos anteriores. Tem sua trajetória ligada a programas de notícias da RBS TV. Há mais de 18 anos na rede, sua participação também dá credibilidade ao especial, trazendo, porém, uma perspectiva nova, mais contemporânea na representação da identidade gaúcha.

Na segunda edição de Bah!(2014), ambas as apresentadoras são distantes do meio tradicionalista, porém, têm uma imagem forte e representativa na condução de seus programas. Cristina Ranzolin é uma das principais apresentadoras da RBS TV, sendo âncora do Jornal do Almoço desde 1996. Sua imagem e seu nome já são reconhecidos no meio, o que facilita com que Bah! Eu sou do Sul seja aceito pelo público. Rodaika Dienstbach insere-se no programa, na tentativa de atrair uma audiência mais jovem, já que tem sua imagem, intimamente, relacionada a esse público. Na emissora, apresenta o Mistura, lidera as coberturas do Planeta Atlântida ${ }^{8}$ e participa em programas de rádio com dicas de moda, beleza e comportamento.

Um elemento que merece destaque são os trajes utilizados. No caso das apresentadoras, nenhuma delas utiliza o tradicional vestido de prenda. Mais próximo a isto, na primeira edição, Shana Müller usa um traje característico da mulher do peão das vacarias (1750-1820) (LISBOA FILHO, 2009), composto de uma saia escura e blusa em tom claro (Figura 5). Mesmo que destoe das vestes tidas como típicas da mulher pelo MTG são mantidas referências que remetem ao vestido de prenda. Já a jornalista Carla Fachim, utiliza elementos da indumentária masculina, veste uma calça e colete marrons, com uma camisa e lenço no pescoço, o que poderia ser considerada uma versão moderna, urbana e feminina do típico traje masculino (Figura 6), principalmente, em épocas atuais, em que o agronegócio ganha espaço diante da pecuária, tendo várias mulheres conduzindo as empresas e negócios.

${ }^{8} 0$ Planeta Atlântida é um festival de música anual organizado pelo Grupo RBS. Teve sua primeira edição em 1996, no Rio Grande do Sul. Em 1998, passou a ser realizado, também, em Santa Catarina. 


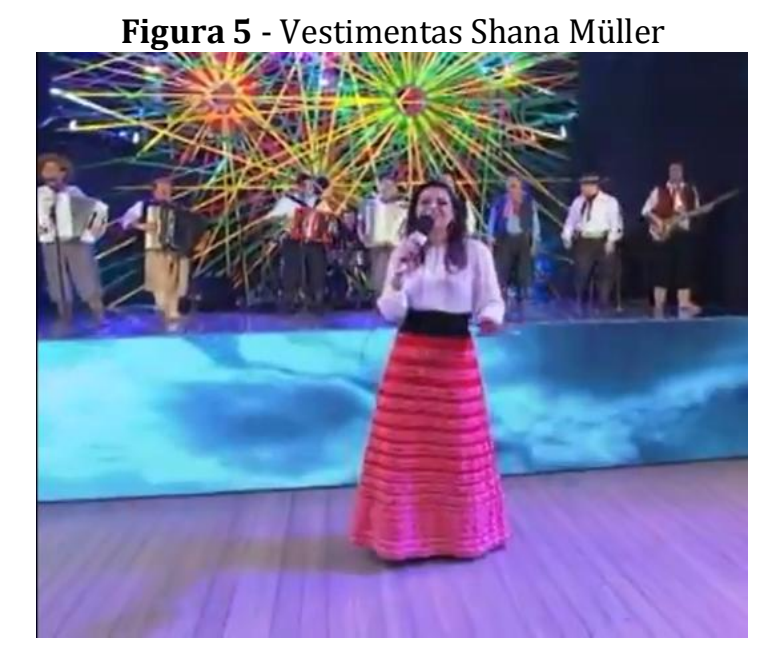

Fonte: Bah! Um programa muito gaúcho (2013).

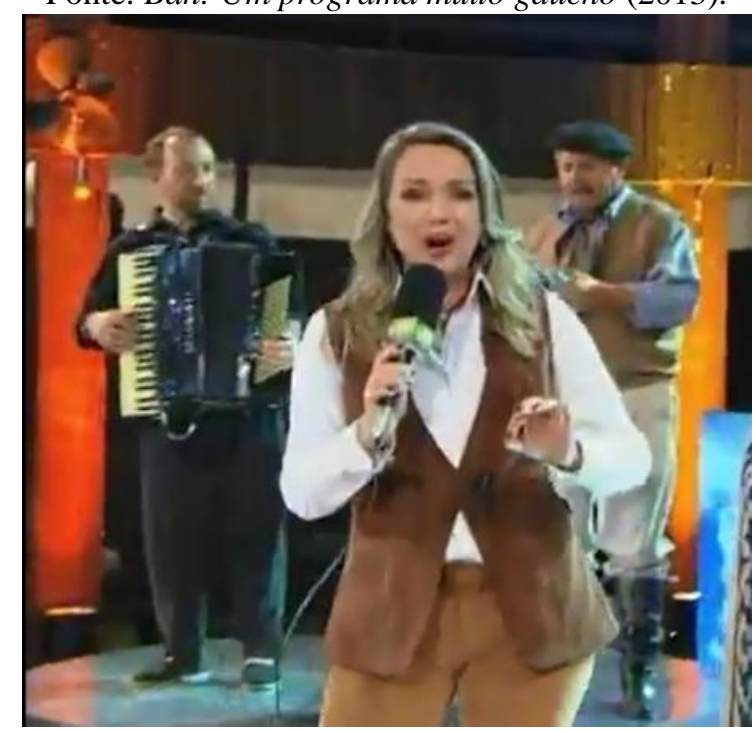

Fonte: Bah! Um programa muito gaúcho (2013).

Este mesmo padrão de vestimentas é utilizado na segunda edição, por Cristina Ranzolin (Figura 7), que veste uma camisa branca com colete marrom e lenço no pescoço, também remetendo aos trajes masculinos. Completando a veste, usa calça jeans justa com uma bota, trazendo elementos mais contemporâneos ao vestuário tradicional do gaúcho. Rodaika está vestida com calça jeans, blusa preta, e diversos acessórios como colares e anéis, suas vestimentas são as que mais se diferem do que é considerado típico gaúcho. 0 elemento que, em sua roupa, faz referência aos trajes gaúchos é a utilização de um xale estampado e com franjas, vestimenta muitas vezes usada por prendas, como uma espécie de agasalho (Figura 7). 
Figura 7 - Vestimentas Rodaika e Cristina Ranzolin

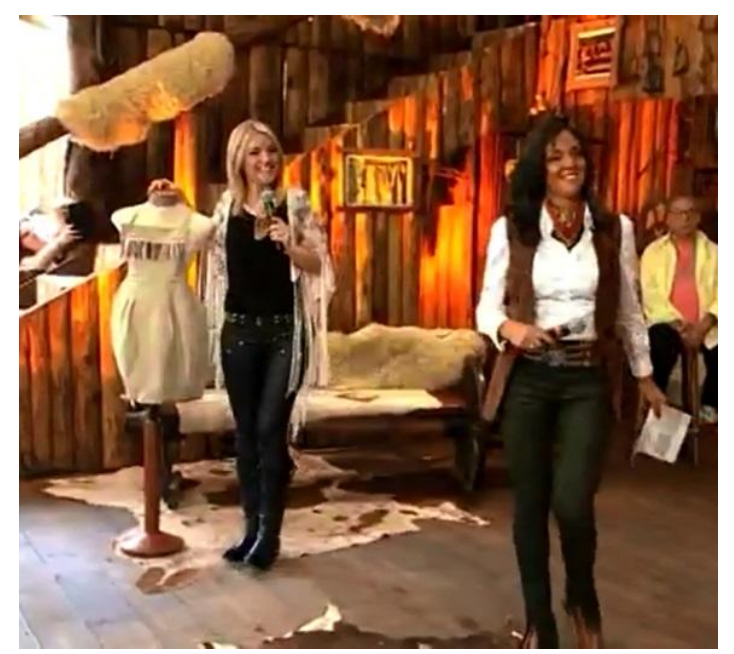

Fonte: Bah! Eu sou do Sul (2014).

0 uso das indumentárias associadas à figura do homem indica uma busca pela sensação de poder, confiança e segurança relacionadas ao sexo oposto. Ou seja, a partir da utilização desses elementos, procura-se minimizar as diferenças existentes entre os sexos, em um contexto de dominação da figura masculina. Esta tarefa torna-se mais evidente com a utilização de apresentadoras já consagradas na emissora para conduzir a atração, já que cada uma, em seus respectivos programas, ocupa uma função de destaque, que apenas foi transferida para os especiais, acrescidos de elementos que remetem à cultura gaúcha mais tradicionalista.

Neste sentido, observa-se a utilização de elementos de fácil reconhecimento no contexto tradicionalista em ambos os programas, como forma de gerar familiaridade e credibilidade com o público, legitimando a nova atração e dando a ela os componentes mais difundidos da identidade gaúcha hegemônica. Por outro lado, apesar dos visíveis elementos que remetem a uma identidade hegemônica, reforçando alguns costumes já associados ao gaúcho, nota-se, também, a presença de componentes mais contemporâneos, que a atualizam.

Por fim, é possível, ainda, destacar alguns elementos presentes na fala dos apresentadores. É perceptível no discurso dos dois especiais a tentativa de mostrar o estado e a cultura gaúcha como um local plural e diversificado. No entanto, na prática, não é o que ocorre. Em nenhum momento dos programas é valorizada outra cultura que não a tradicionalista. Todos aqueles que participaram da formação do estado e até da Revolução Farroupilha, feito tão aclamado em Bah!, são deixados em segundo plano quando não, 
ocultados. Nos programas, as mulheres do Rio Grande do Sul não são exaltadas, sua importância não é valorizada. Elas não estão completamente excluídas do discurso, porém, quando aparecem, enquadram-se dentro do estereótipo hegemônico da mulher gaúcha, sempre como apoio ao homem.

Dessa forma, a mulher gaúcha é apresentada de forma idealizada visto que deve ser bela, se interessar por "assuntos de mulheres", como moda e, naturalmente, ela não saberia montar a cavalo da mesma forma que um homem. Além disso, um dos convidados declara que "com uma loira bonita como você [Carla Fachim] já saio dançando e atropelando na festa". Perspectiva essa que carrega consigo certa objetificação da mulher, traduz a ideia de uma "mulher enfeite", que está lá para adornar os bailes e alegrar os peões. Esse modo machista de tratar as mulheres é tão arraigado socialmente que é aceito por muitos, inconscientemente, sem questionamentos, sendo ainda, apreciado por alguns como uma das características do "ser homem gaúcho".

Outro aspecto interessante a ser observado é quando, no segundo Bah! (2014), Rodaika apresenta uma reportagem sobre customização de vestimentas, em um "desafio gaudério-fashion". Fica implícito em seu discurso que esse tema tem tudo a ver com as mulheres, ou seja, um assunto relacionado ao mundo feminino. Além disso, outro ponto a ser destacado é quando Cristina Ranzolin questiona se Neto Fagundes sabe montar a cavalo e ele responde que não. Nesse momento, ela afirma que "eu esperava ouvir isso da Rodaika e não do Neto". Em uma lógica simples, Neto Fagundes, por ser homem deveria saber montar e Rodaika não.

Todas essas falas e recortes de texto juntam-se em um cenário muito mais amplo, dando sentido ao discurso apresentado no programa. As valorações, implícitas ou explícitas são carregadas de pensamentos, ideologias, visões de mundo e ideias estereotipadas e hegemônicas. Mesmo com a tentativa de ser plural, alguns desses aspectos ainda estão extremamente arraigados nos discursos utilizados.

\section{Considerações Finais}

Os especiais Bah! Um programa muito gaúcho e Bah! Eu sou do Sul, foram criados para a comemoração do 20 de setembro, data em que se celebra a Revolução Farroupilha. Este enfrentamento ajudou a moldar algumas das principais características ditas da identidade gaúcha. 0 gaúcho deveria ser bravo, viril, corajoso, estar sempre pronto para a batalha. Às mulheres, caberia ficar na sombra das conquistas. Nesse contexto, percebe-se 
que os programas Bah! Utilizam-se, majoritariamente, do estereótipo do gaúcho. Os temas abordados, em geral, as danças típicas, a culinária e os costumes, são, comumente, associados ao estado. 0 programa inova ao trazer atrações mais variadas, entretanto, mesmo com as pequenas aberturas, segue perpetuando a imagem hegemônica.

A presença da mulher aparece, neste contexto, principalmente, na figura das apresentadoras e ali permanece. 0 programa, em nenhuma das edições, abordou a presença delas na história gaúcha, assim como pouco fala da importância dos escravos negros e de outras minorias. Dessa forma, são poucos os espaços para debate e problematização da figura feminina ou de qualquer outra representação que se diferencie da imagem tradicionalista. Sendo assim, percebe-se que, por diversas vezes, a figura feminina é ocultada. Mesmo que elas sejam as apresentadoras, estejam em número maior, participem de todos os shows, apresentações e danças das atrações, nenhum desses conteúdos é direcionado a elas, destacando e valorizando sua presença e participação, não só histórica como também nos dias atuais, dentro da sociedade gaúcha. Ou seja, as mulheres no programa estão lá para compor e reafirmar uma história masculina, não para serem protagonistas. Nesse sentido, o que se apresenta nos especiais é um falso protagonismo: as mulheres são mostradas, estão presentes, atualizam a representação tradicional, porém, não a modificam, pelo contrário, a fortalecem.

Entretanto, mesmo que a temática do programa não as contemple, suas figuras, a frente das atrações, revelam que alguns paradigmas já começam a se alterar. Por outro lado, ainda são muito fortes os traços que a masculinizam, a fim de se encaixar nesse padrão, perceptível na figura das apresentadoras por meio de algumas de suas vestes, posturas, falas e comportamentos. No entanto, ao colocar quatro mulheres para apresentar os especiais, rompe-se com a ideia da submissão feminina e atualiza-se a imagem da mulher gaúcha frente a uma identidade, mesmo que com traços masculinos. Essa masculinização, porém, surge na tentativa de marcar um lugar de fala, um espaço e posição de poder semelhante às possuídas, até então, pelos homens. Contudo, esse processo atua na contramão de uma perspectiva de empoderamento feminino, já que, de certo modo, apenas reforça e perpetua a ideia de que não basta "ser mulher" para conseguir algo, é preciso "ser mulher" e "agir como homem". Essa ideia de "agir como homem", entretanto, relaciona-se, erroneamente, a comportamentos e atitudes que, no senso comum, eram tidos como características masculinas, como a independência, as posições de poder e liderança e a exposição e participação na vida pública. 
Observam-se assim, que o programa apresenta uma identidade feminina estereotipada da mulher gaúcha, uma representação referente à figura da companheira ideal para o gaúcho, também estereotipado. Esses elementos observados nos programas não se restringem, porém, ao meio televiso e a um produto midiático. São o retrato de uma sociedade que tem como característica uma identidade com referências no masculino, o que dificulta a abertura de espaços para reflexão sobre a condição das mulheres no atual contexto. Por fim, percebe-se que os especiais atuam na intenção de perpetuar uma identidade hegemônica e masculina, transmitindo uma falsa ideia de empoderamento feminino, apenas na busca por gerar audiência e reconhecimento. Assim, ao buscar evidenciar o protagonismo das mulheres, colocando-as em postos masculinos e de comando, a emissora e o programa cumprem uma tarefa mercadológica, atingindo um público masculino admirador dessas personagens, gerando identificação com as mulheres que, nessas figuras, se veem representadas através de uma imagem de fortaleza e independência. Por outro lado, esse falso protagonismo encobre inúmeras situações problemáticas; desconsiderando o pluralismo de interesses sociais e formas de poder envolvidas nessas construções; transmitindo a perspectiva de que se valoriza e representa toda a população feminina, sem levar em conta sua diversidade e pluralidade.

\section{Referências}

BAH! Eu sou do Sul. Apresentado por Rodaika Dienstbach, Cristina Ranzolin, Neto Fagundes. Porto Alegre: RBS TV, 20 set. 2014. 1h10min.

BAH! Um programa Muito gaúcho. Apresentado por Shana Müller, Carla Fachim, Neto Fagundes. Porto Alegre: RBS TV, 20 set. 2013. 1h38min.

BEAUVOIR, Simone de. 0 segundo sexo: fatos e mitos. São Paulo: Difusão Europeia do Livro, 1970.

BORTOLUZZI, Cristiane Greiwe et al. Do tradicional à customização: a representação feminina do programa televisivo Galpão Crioulo. In: ENCUENTRO PANAMERICANO DE COMUNICACION, 6., 2013, Córdoba. Anais... Córdoba: CONAPAM, 2013.

BUTLER, Judith. Problemas de gênero: feminismo e subversão da identidade. Rio de Janeiro: Civilização Brasileira, 2015.

CASETTI, Francesco; CHIO, Frederico di. Análisis de la televisión: instrumentos, métodos y prácticas de investigación. Barcelona: Paidós, 1999. 
CASTELLS, Manuel. 0 poder da identidade: a era da informação: economia, sociedade e cultura. São Paulo: Paz e Terra, 1999.

CÔRTES, Carlos Paixão. As vestes do o Laçador. Porto Alegre, 6 de março de 2011. Disponível em: <http://paixaocortes.blogspot.com.br/2010/10/o-lacador-bem-depilcha.html> Acesso em 02 jan. 2017.

CUCHE, Denys. A noção de cultura nas ciências sociais. Bauru: Edusc, 2002.

DUTRA, Cláudia P. A prenda no imaginário tradicionalista. 2002. Dissertação (Mestrado em História)-Programa de Pós-Graduação em História, Faculdade de Filosofia e Ciências Humanas, Pontifícia Universidade Católica do Rio Grande do Sul, Porto Alegre, 2002.

ESCOSTEGUY, Ana Carolina. Circuitos de cultura/circuitos de comunicação: um protocolo analítico de integração da produção e da recepção. Comunicação, Mídia e Consumo, São Paulo, v. 4, n. 11, p. 115-135, nov. 2007.

ESCOSTEGUY, Ana Carolina. Os estudos culturais. In: HOHLFELD, A.; MARTINO, L. C.; FRANÇA, V. V. F. (Org.). Teorias da comunicação: conceitos, escolas e tendências. 8. ed. Petrópolis: Vozes, 2001.

FARAH, Marta Ferreira Santos. Gênero e políticas públicas. Estudos Feministas, Florianópolis, v. 12, n. 1, p. 47-71, jan./abr 2004.

GRAMSCI, Antonio. Cadernos do cárcere. Rio de Janeiro: Civilização Brasileira, 2002.

HALL, Stuart. A Centralidade da Cultura: notas sobre as revoluções culturais do nosso tempo. Revista Educação e Realidade, 22 (2), jul./dez. Porto Alegre, 1997.

HALL, Stuart. Estudos culturais e seu legado teórico. In: SOVIK, Liv (Org.). Da diáspora: identidades e mediações culturais. Belo Horizonte: Humanitas, 2003.

HINERASKY, Daniela Aline. A produção de teledramaturgia regional: um estudo sobre a identidade cultural nas séries de ficção da RBS TV. Revista Acadêmica do Grupo Comunicacional de São Bernardo, São Bernardo do Campo, v. 2, n. 3, jan./jun. 2005.

INSTITUTO BRASILEIRO DE GEOGRAFIA E ESTATÍSTICA. Censo. Rio de Janeiro, 2010.

JACOBINA, Eloá; KÜHNER, Maria Helena (Org.). Feminino / masculino: no imaginário de diferentes épocas. Rio de Janeiro: Bertrand Brasil, 1998.

JOHNSON, Richard. 0 que é, afinal, estudos culturais? In: SILVA, Tomaz Tadeu da (Org.). 0 que é, afinal, estudos culturais? Belo Horizonte: Autêntica, 2006.

LISBOA FILHO, Flavi Ferreira. Mídia regional: gauchidade e formato televisual no Galpão Crioulo. 2009. Tese (Doutorado em Comunicação) - Programa de Pós-Graduação em Ciências da Comunicação, Universidade do Vale dos Sinos, São Leopoldo, 2009. 
OLIVEN, Ruben George. A parte e o todo: a diversidade cultural no Brasil-nação. Petrópolis: Vozes, 1992.

PESAVENTO, Sandra Jatahy. Mulheres e história: a inserção da mulher no contexto cultural de uma região fronteiriça. Revista de Literatura Brasileira, Florianópolis, n. 23, p. 54-72, 1991.

ROCHA, Simone Maria. Os estudos culturais e a análise cultural da televisão: considerações teórico-metodológicas. Revista Interamericana de Comunicação Midiática, Santa Maria, v. 10, n. 19, 2011.

SCHMIDT, Rita Terezinha. Repensando a cultura, a literatura e o espaço da autoria feminina. In: NAVARRO, Márcia Hoppe (Org.). Rompendo o silêncio: gênero e literatura na América Latina. Porto Alegre: Editora da Universidade/UFRGS, 1994.

SCOTT, Joan. Gênero: uma categoria útil de análise histórica. Revista Educação e Realidade, Porto Alegre, v. 20, n. 2, p. 71-99, jul./dez. 1995.

SOUZA, José Carlos Aronchi de. Gêneros e formatos na televisão brasileira. São Paulo: Summus, 2004.

WILLIAMS, Raymond. Marxismo e literatura. Rio de Janeiro: Zahar, 1979.

WOODWARD, K. Identidade e diferença: uma introdução teórica e conceitual. In: SILVA, Tomaz Tadeu da (Org.). Identidade e diferença: a perspectiva dos estudos culturais. Petrópolis: Vozes, 2000.

\title{
Women on the specials Bah!: the identity of gaúchos and female representation
}

\begin{abstract}
The article aims to analyze how RBS TV represents the female identity, from the speech enunciated by its television programs Bah! Um programa muito gaúcho and Bah! Eu sou do Sul. Based on cultural analysis and having as an analytical operator Johnson's Circuit of Culture, we seek to relate the presence and representation of these women in a traditionalist context. We noticed that the program breaks with the premise of female subordination at the same time that it diffuses the gaucho stereotype.
\end{abstract}

\section{Keywords}

Cultural Studies. Genre. Representation.

Recebido em 09/05/2016

Aceito em 23/10/2016 